\title{
Impacto del programa Jóvenes en Acción en la deserción estudiantil en tiempos de Covid-19
}

Impact of the youth in Action Program on student desertion in times of Covid-19

\author{
RINCON, Isbelia K. ${ }^{1}$ \\ SUAREZ, Sir A. ${ }^{2}$ \\ SUAREZ CASTRILLON, Albert M. ${ }^{3}$
}

\begin{abstract}
Resumen
Este artículo analiza el impacto del programa Jóvenes en Acción en la deserción estudiantil en tiempo de covid-19 en la Universidad Francisco de Paula Santander Ocaña. Para tal fin, se recabo la información de los estudiantes matriculados en el primer y segundo semestre del 2019 y 2020 . Los resultados revelaron que el índice de deserción en épocas de pandemia fue del 8.5\%, a pesar de las ayudas extraordinarias otorgadas por el Gobierno Nacional para mitigar el abandono escolar universitario.

Palabras clave: deserción estudiantil, población vulnerable, jóvenes en acción, covid-19.

Abstract

This article analyzes the impact of the youth in action program on student desertion in the time of covid-19 at the Francisco de Paula Santander Ocaña University. For this purpose, information was collected on students enrolled in the first and second semesters of 2019 and 2020. The results revealed that the dropout rate in times of pandemic was $8.5 \%$, despite the extraordinary aid granted by the Government National to mitigate college dropouts.

key words: student desertion, vulnerable population, youth in action, covid-19.
\end{abstract}

\section{Introducción}

La gran oferta de los programas académicos en las instituciones de educación superior en Colombia, ha generado un crecimiento del $1.2 \%$ anual en la matrícula (Acevedo, Zuluaga, \& Jaramillo, 2010); lo que conlleva a reconocer que la educación universitaria es un pilar para el desarrollo social, político, cultural, económico, tecnológico y científico para un país.

A finales del año 2012 mediante la resolución 1970, en Colombia se da inicio al programa Jóvenes en Acción una apuesta del gobierno nacional para incentivar y fortalecer la formación de los jóvenes entre los 14 y 28 años de edad en condición de pobreza o vulnerabilidad, mediante el modelo de transferencia monetaria condicional,

\footnotetext{
${ }^{1}$ Docente. Programa Ingeniería de Sistemas. Universidad Francisco de Paula Santander Ocaña. Grupo de Investigación Grucite. ikrinconp@ufpso.edu.co 2 Docente. Programa Ingeniería de Sistemas. Universidad Francisco de Paula Santander Ocaña. Grupo de Investigación Grucite. sasuarezc@ufpso.edu.co ${ }^{3}$ Docente. Programa Ingeniería Mecánica. Universidad de Pamplona. Grupo de Investigación Gimup. albertmiyer@unipamplona.edu.co
} 
cuyo objetivo es el acceso y la permanecía en la educación superior y fortalecimiento de competencias transversales (Resolución 1970, 2012).

Tal finalidad del programa, es disminuir la deserción estudiantil, el cual es un fenómeno altamente complejo y de impactos negativos para los agentes involucrados en ello (Departamento Administrativo para la Prosperidad Social, 2020); es así, que mediante entregas de incentivos denominadas R1_matrícula y R2_permanencia y excelencia, a cada beneficiario les giran una suma de dinero para garantizar el acceso y permanencia en la educación superior por semestre.

En consecuencia al estado de emergencia generado por el COVID-19 a nivel mundial, el Departamento de Prosperidad Social, crea la entrega de transferencias monetarias no condicionadas, adicional y extraordinaria a los participantes del programa jóvenes en acción (Resolución 01169, 2020), con el fin de mitigar los impacto negativos que ha generado la crisis en el sector educativo; por otro lado, el boletín técnico sobre el costo de la educación superior para el primer semestre del 2020, indica que en comparación con el primer semestre del año anterior, los costos para estudiar en Colombia aumentaron en 1.4\% (Dane, 2020).

Uno de las variables fundamentales para la deserción estudiantil se produce por la influencia de factores económico y personales (Sánchez, Barbosa , \& Castilla, 2017); esta variable hace que los gobiernos a nivel mundial, generen estrategias que fortalezcan la permanencia en las instituciones de educación superior y así controlar o disminuir esta deserción y más en momentos de emergencia por Covid-19.

En Latinoamérica, el abandono de los estudios universitarios es un fenómeno en aumento en la mayoría de los países; por esta razón, se le considera uno de los problemas que se investiga con mayor prioridad (Sevilla, Puerta Echavarría, \& Davila Molina, 2010). Teniendo en cuenta este fenómeno, Colombia es el país que se destaca con mayor información científica, seguido de México, Chile y Argentina, países donde se orientan a investigar el porcentaje de desertores e informar sobre las variables que lo ocasionan; así mismo, concientizan que la deserción es un problema de interés gubernamental (Sánchez, Barbosa , \& Castilla, 2017).

En estudios realizados en las Universidades de Chile, se identificó que tres de cada diez estudiantes que se matriculan desertan de la institución en el primer año, estos datos altamente alarmantes. Dedujeron que el abandono escolar depende de la falta de recursos económicos y como paliativo se pusieron en marcha estrategias de retención como talleres en habilidades de estudio, apoyo psicoeducativo y nivelación del conocimiento, lo cual, concluye esta investigación, que no es suficiente para asegurar la permanencia de los estudiantes más vulnerables (Navarrete, Candia, \& Puchi, 2013).

En este mismo contexto, Díaz (2008) señala que la retención estudiantil se traduce en beneficios sociales e institucionales y que los estudiantes que no desertan y logran su título universitario, no solo obtienen salarios, también presentan mayores expectativas laborales, aspiran a cargos gerenciales, beneficios amparados por el marco legislativo y tienen la visión de continuar con estudios de posgrados.

En la Unión Europea la tasa de deserción fue del 10.6\% para el 2019 y España tiene el mayor índice de abandono escolar con el 17.9\% en el 2018, a pesar de que ha conseguido reducir el abandono entre los jóvenes de 18 y 24 años que dejan de forma prematura sus estudios, aún sigue en aumento está problemática (Europa Press, 2019).

En Colombia también han existido otros programas que amplían el acceso y la permanecía a la educación superior de alta calidad a jóvenes que provienen de hogares económicamente vulnerables, es así que en el 2014 se crea el programa Ser Pilo Paga y después de seis años, se concluye que su impacto ha sido positivo, teniendo en cuenta que la posibilidad de un joven de estrato uno de ingresar a la universidad aumentó en un 182\% y un $97 \%$ para jóvenes de estrato dos y se hace necesario resaltar que la deserción a nivel nacional en el primer año se redujo en un $18 \%$ (Jaramillo, 2020). 
En este mismo orden de ideas, para el año 2018 el gobierno nacional lanza el programa Generación E, el cual le da continuidad el programa Ser Pilo Paga; por medio del convenio interadministrativo No. 1166 el Ministerio de Educación se sigue durante cuatro años fomentar el acceso, permanencia y graduación a la educación superior de estudiantes del país en condición de vulnerabilidad económica y víctimas del conflicto armado, a través de subsidios e incentivos para cursar estudios de pregrado en Instituciones de Educación Superior públicas, el cual asegura que más jóvenes de bajos recursos tengan mayores oportunidades de acceder a la educación superior (Ministerio de Eduación, 2019).

Evaluando los estudios anteriores, se observa que una de las variables que afecta la deserción es el factor socioeconómico en los estudiantes. En consecuencia por el estado de emergencia generado por el Covid-19 en el primer trimestre del año 2020, unos 34 millones de empleos se perdieron en América Latina y el Caribe, y en Colombia el desempleo llegó al 20.2\% desde que comenzó el estado de aislamiento en el mes de marzo (Dinero, 2020); por tal motivo, el objetivo de esta investigación es identificar si las ayudas del gobierno por medio del programa Jóvenes en Acción ha permitido que los estudiantes vulnerables de la universidad Francisco de Paula Santander Ocaña, contiene con su programa académica en tiempo de pandemia.

\section{Metodología}

La población de estudio involucrada, fueron los beneficiaros del programa Jóvenes en Acción matriculados en la Universidad Francisco de Paula Santander Ocaña, en los periodos comprendidos entre el primer y segundo semestre del año 2019 y el 2020. Cabe resaltar, que de acuerdo al Departamento de Prosperidad Social estos beneficiarios son estudiantes vulnerables por ser víctimas del conflicto armado, población indígena, jóvenes con medida de protección del Instituto de Bienestar Familiar y población censada por el sistema de selección de beneficiarios para programas sociales. Aunado a esto, los estudiantes se encuentran matriculados desde el primero al décimo semestre y sus edades oscilan entre los 16 a 28 años de edad.

En esta investigación se adoptó una estrategia descriptiva de tipo selectivo, teniendo en cuenta que la información utilizada son los reportes semestrales generados por la Universidad al Departamento de Prosperidad Social. Estos archivos son el insumo para la verificación de compromisos posterior al proceso de liquidación y entrega del beneficio. Además, para este estudio, se describió cómo afecta el estado de emergencia por covid19 versus la variable de ayudas económicas extraordinarias que otorga el Gobierno Nacional por medio del programa Jóvenes en Acción, para prevenir la deserción en estos momentos de pandemia.

El procedimiento utilizado en primera media, fue la obtención de las bases de datos de matrícula de los beneficiaros en los periodos comprendidos entre el 2019 y 2020, esta información fue suministrada directamente por la oficina de división de sistemas de la Universidad.

Una vez se tiene los archivos, se importa a un sistema de gestión de datos y se toma como llave primaria los códigos de los estudiantes asignados por el programa jóvenes en acción; luego se crean las consultas de no coincidentes, en donde se cruzan los registros de matrícula por semestre académico. Así es como se obtienen los datos de los estudiantes desertores.

De los resultados anteriores, se procedió a la aplicación de la fórmula propuesta por Acevedo (2015), que identifica el índice de deserción. Esto implicó dividir la cantidad total de estudiantes desertores entre el total de estudiantes matriculados y multiplicar el resultado por cien; al mismo tiempo, se generó el promedio de deserción por semestre académico, sexo y programa. 


\section{Resultados}

Para establecer la deserción en los estudiantes, se analizó la matrícula del primer y segundo semestre del 2019 y se comparó con la matrícula del 2020. En la Tabla 1 se aprecia que el número de matrícula aumentó en 214 beneficiarios, lo que significa un $6.1 \%$ en los primer semestre del 2019 al 2020 . Esto se debe a que el Departamento de Prosperidad Social aumentó su cobertura para este año, ingresando en el primer semestre más de 87.417 nuevos beneficiarios en toda Colombia, permitiendo el acceso al programa de estudiantes que se encuentran en los semestres del quinto al décimo, condición que se tenía restringida años anteriores, en donde solo podían ingresar estudiantes del primero al cuarto semestre (Comunicaciones, 2020).

Tabla 1

Beneficiarios del programa Jóvenes en Acción matriculados en la Universidad

Francisco de Paula Santander Ocaña para los periodos 2019-2020

\begin{tabular}{|c|c|c|}
\hline \multirow{2}{*}{ Año } & \multicolumn{2}{|c|}{ Número de Beneficiarios Matriculados } \\
\cline { 2 - 3 } & Primer semestre & Segundo Semestre \\
\hline 2019 & 3271 & 3260 \\
\hline 2020 & 3485 & 3270 \\
\hline
\end{tabular}

Fuente: elaboración propia

Para establecer el comportamiento del fenómeno de estudio, se halló el índice de deserción -IDS. En la Tabla 2 se evalúa que el IDS semestral de los beneficiarios matriculados es alto en el primer semestre del 2020 con un $10 \%$ y en tanto, que para un año atrás era del $6 \%$. En cambio en los segundos semestres del 2019 y 2020 , el índice de deserción fue el mismo 7\%; en líneas generales, el promedio de deserción de un año a otro es del 8\%.

Tabla 2

Índice de deserción semestral (IDS) de los estudiantes beneficiarios del programa Jóvenes en Acción matriculados en el 2019-2020

\begin{tabular}{|c|c|c|c|c|}
\hline Año & $2019-1$ & $2019-2$ & $2020-1$ & $2020-2$ \\
\hline Ingresantes (n) & 3271 & 3260 & 3485 & 3270 \\
\hline Desertores & 212 & 235 & 362 & 215 \\
\hline IDS\% & $6 \%$ & $7 \%$ & $10 \%$ & $7 \%$ \\
\hline Promedio IDS 2019-2020 & \multicolumn{5}{|c|}{$8 \%$} \\
\hline
\end{tabular}

Fuente: elaboración propia

En consecuencia a lo anterior, en la Tabla 3 se presenta el índice de deserción en tiempo de Covid-19 el cual es del 8.5\%, una cifra elevada en comparación con el año anterior que dio 6.8\%. A pesar que el Departamento de Prosperidad Social les está girando los pagos ordinarios que corresponden a R1_matrícula por un valor de $\$ 400.000$ peso y R2_permanencia y excelencia por un valor de $\$ 400.00$ pesos y si el promedio ponderado del estudiante es superior a 4.0 les aumenta a $\$ 600.000$ pesos, y los pagos extraordinarios que se entregan cada dos meses por un valor de $\$ 356.000$.

Lo anterior significa, que desde el mes de marzo que se comenzó el aislamiento preventivo por Covid-19 hasta el mes de octubre, un joven beneficiario ha recibido un promedio de $\$ 2.224 .000$ pesos. 
Tabla 3

Índice de deserción semestral (IDS) de los estudiantes beneficiarios del programa Jóvenes en Acción matriculados en el 2019-2020

\begin{tabular}{|c|c|c|}
\hline Año & $2020-1$ & $2020-2$ \\
\hline Ingresantes (n) & 3485 & 3270 \\
\hline Desertores & 362 & 215 \\
\hline IDS\% & $10 \%$ & $7 \%$ \\
\hline Promedio IDS en tiempo de Covid-19 & \multicolumn{2}{|c|}{$8.5 \%$} \\
\hline
\end{tabular}

Fuente: elaboración propia

En cuanto a los semestre donde más desertan los estudiantes en tiempo de pandemia, la Tabla 4 indica que el primer semestre académico tiene el porcentaje de deserción más alto con el $16 \%$, lo que significa que los nuevos beneficiaros no pudieron continuar estudiando en el segundo semestre del 2020; luego siguen los estudiantes del séptimo semestre con el $7 \%$ y en tercera línea están los estudiantes del cuarto semestre con el $6 \%$; los semestre con menos deserción son el quinto y el noveno semestre con un porcentaje del $1 \%$.

En comparación con el año anterior, los estudiantes matriculados en el primer semestre fueron los más desertores con un porcentaje del $11.9 \%$, seguidos por los del sexto semestre con $10.6 \%$ y los del segundo semestre con el $6.8 \%$.

Lo anterior, demuestra que los estudiantes matriculados en el primer semestres, presenta la mayor tasa de deserción de un año a otro.

Tabla 4

Promedio de deserción por programa académico en tiempo de Covid-19

\begin{tabular}{|c|c|c|}
\hline Semestre Académico & Beneficiarios Desertores & Porcentaje \\
\hline 1 & 34 & $16 \%$ \\
\hline 2 & 7 & $3 \%$ \\
\hline 3 & 10 & $5 \%$ \\
\hline 4 & 12 & $6 \%$ \\
\hline 5 & 2 & $1 \%$ \\
\hline 6 & 6 & $3 \%$ \\
\hline 7 & 16 & $7 \%$ \\
\hline 8 & 11 & $5 \%$ \\
\hline 9 & 3 & $1 \%$ \\
\hline 10 & 10 & $5 \%$ \\
\hline
\end{tabular}

Fuente: elaboración propia

La Tabla 5, contextualiza la deserción de acuerdo al sexo. Los hombres son los que mas desertan con un promedio del 59\%. Al igual que los resultados de la tabla anterior, el semestre donde más desertan es el primero, seguido por el séptimo, tercero y cuarto semestre; es importante resaltar, que en los semestres del quinto y noveno, no se presentaron deserciones. En cambio las mujeres tiene un porcentaje de deserción del $41 \%$, y los semestres donde más desertan es en el primero y octavo semestre. Al contrario de los hombres, las mujeres desertaron en todos los semestres. 
Tabla 5

Deserción de los beneficiarios del Programa Jóvenes en Acción por sexo en tiempo de Covid-19

\begin{tabular}{|c|c|c|c|c|c|c|c|c|c|c|c|}
\hline \multirow{2}{*}{ Sexo } & \multicolumn{10}{|c|}{ Semestre } & \% \\
\cline { 2 - 24 } & $\mathbf{1}$ & $\mathbf{2}$ & $\mathbf{3}$ & $\mathbf{4}$ & $\mathbf{5}$ & $\mathbf{6}$ & $\mathbf{7}$ & $\mathbf{8}$ & $\mathbf{9}$ & $\mathbf{1 0}$ & \\
\hline Femenino & 7 & 3 & 3 & 5 & 2 & 2 & 8 & 6 & 3 & 6 & $41 \%$ \\
\hline Masculino & 27 & 4 & 7 & 7 & & 4 & 8 & 5 & & 4 & $59 \%$ \\
\hline
\end{tabular}

Fuente: elaboración propia

La Universidad Francisco de Paula Santander Ocaña, actualmente tiene cuatro facultades conformadas por 10 programas académicos. En la Tabla 6 se mide la deserción en tiempo de pandemia en cada uno de estos programas. En ella se evidencia que el programa de derecho tiene el primer puesto por deserción con el 16\%, en el segundo el programa de contaduría pública con el 15\% y el tercer lugar el programa de Ingeniería de sistemas con el 12\%; el programa que presenta menor deserción es el de zootecnia con el 5\%.

En comparación con el año anterior, la deserción se vio marcada en el programa de contaduría pública en un $18.3 \%$, seguida por Ingeniería ambiental e ingeniería Civil con el $13.6 \%$.

Lo que indica, que en tiempo de covid-19 el programa de contaduría pública sigue presentado altos índices de deserción.

Tabla 6

Deserción de los beneficiarios del Programa Jóvenes en Acción por programa académico en tiempo de Covid-19

\begin{tabular}{|c|c|c|}
\hline Facultad & Programa & Porcentaje \\
\hline \multirow{3}{*}{ Facultad de Ingenierías } & Ingeniería Mecánica & $7 \%$ \\
\hline & Ingeniería Civil & $11 \%$ \\
\hline & Ingeniería de Sistemas & $12 \%$ \\
\hline \multirow{2}{*}{$\begin{array}{l}\text { Facultad de Educación } \\
\text { Artes y Humanidades }\end{array}$} & Comunicación Social & $11 \%$ \\
\hline & Derecho & $16 \%$ \\
\hline \multirow{3}{*}{$\begin{array}{c}\text { Facultad de Ciencias } \\
\text { Administrativas y } \\
\text { Económicas }\end{array}$} & Tecnología en Gestión Comercial y Financiera & $7 \%$ \\
\hline & Contaduría Pública & $15 \%$ \\
\hline & Administración de Empresas & $7 \%$ \\
\hline \multirow{2}{*}{$\begin{array}{c}\text { Facultad de Ciencias } \\
\text { Agrarias y del Ambiente }\end{array}$} & Ingeniería Ambiental & $10 \%$ \\
\hline & Zootecnia & $5 \%$ \\
\hline
\end{tabular}

Fuente: elaboración propia

\section{Conclusiones}

El programa Jóvenes en Acción suministró las ayudas extraordinarias en época de la pandemia para mitigar los problemas de deserción en las instituciones de educación pública, teniendo en cuenta que la tasa de desempleo ha llegado a los más altos índices en el primer semestre del 2020 y por lo tanto, los estudiantes no podrán costear sus estudios universitarios.

El resultado de esta investigación, indica que el índice de deserción de los beneficiarios del programa jóvenes en acción vinculados a la universidad Francisco de Paula Santander Ocaña en el último año es del 8\%.

Los estudiantes que cursaban el primer semestre en el 2019 fueron los que presentaron una alta deserción, con un porcentaje del 16\%, lo cual indica que para el segundo semestre del 2020 estos jóvenes universitarios abandonaron sus estudios; de acuerdo con Donoso (2007), un estudiante que permanece en el sistema educativo es aquel que percibe que estudiar le generan mayores beneficios sociales y económicos, a diferencia de los 
desertores, que perciben que estudiar genera beneficios inferiores a los derivados de actividades distintas y por lo tanto, es posible que se retiren de la institución universitaria.

En este mismo orden de ideas, el $59 \%$ de los hombres matriculados en el primer semestre no continuaron sus estudios y en caso de las mujeres fue del 41\%; así mismo, el programa de derecho tiene la tasa más alta de deserción con $16 \%$, seguido del programa de contaduría pública con el $15 \%$. Es importante resaltar, que este último programa, tiene la tasa de deserción más alta del año anterior.

Para concluir, el Gobierno Nacional ha entregado desde que inicio el estado de emergencia en Colombia por Covid-19 un promedio de $\$ 2.224 .000$ pesos por beneficiario, pero el índice de deserción entre el primer semestre y el segundo del 2020 fue del $8.5 \%$, un porcentaje dos puntos por encima del año anterior que fue del $6.8 \%$, lo que indica que la deserción es alta y estas ayudas, no han logrado mitigar esta problemática.

\section{Referencias bibliográficas}

Acevedo , S., Zuluaga, F., \& Jaramillo, A. (Junio de 2010). Determinantes de la demanda por educací on superioren Colombia. Revista de Economía del Rosario, 11(1), 121-148.

Acevedo, D., Torres, J., \& Tirado, D. (2015). Análisis de la Deserción Estudiantil en el Programa Ingeniería de Alimentos de la Universidad de Cartagena durante el Periodo Académico 2009 - 2013. Formación universitaria, 1(35), 35-42.

Comunicaciones, O. (15 de Octubre de 2020). Prosperidad Social. Obtenido de Prosperidad Social inició cuarta entrega de incentivos a más de 359 mil Jóvenes en Acción:

https://prosperidadsocial.gov.co/Noticias/prosperidad-social-inicio-cuarta-entrega-de-incentivos-a-masde-359-mil-jovenes-en-accion/

Dane. (2020). Boletín Técnico Indice del Costo de la Eduación Superior (ICES). Bogotá: Sistema Estádistico Nacional.

Departamento Administrativo para la Prosperidad Social. (2020). Manual Operativo Programa jóvenes en Acción. Bogotá: Prosperidad Social.

Díaz Peralta, C. (2008). Modelo conceptual para la deserción estudiantil universitaria chilena. Estudios pedagógicos, 34(2), 65-86.

Dinero. (30 de Septiembre de 2020). Unos 34 millones de empleos se perdieron en Latinoamérica con la covid. Obtenido de Dinero: https://www.dinero.com/internacional/articulo/oit-unos-34-millones-de-empleos-seperdieron-en-america-latina-con-la-pandemia/301935

Donoso , S., \& Schiefelbein, E. (2007). Analysis of explicative models of student's retention at the University: A vision from the social inequality. Estudios pedagógicos (Valdivia), 1(33), 7-27.

Europa Press. (13 de Octubre de 2019). Europa Press. Obtenido de España vuelve a estar a la cola en abandono escolar en la UE, según Eurostat: https://www.europapress.es/sociedad/educacion-00468/noticia-espanavuelve-estar-cola-abandono-escolar-ue-eurostat-20190426170724.html

Jaramillo, S. (12 de Febrero de 2020). Económico, Un blog Latinoamericáno de Economía y Política. Obtenido de Desertores y rezagados en educación superior: ¿quién podrá defenderlos?: https://focoeconomico.org/2020/02/12/desertores-y-rezagados-en-educacion-superior-quien-podradefenderlos/ 
Ministerio de Eduación. (2019). Reglamento Operativo Componente de Equidad, Avance en la Gratuidad en las Instituciones de Educación Superior Públicas. Bogotá: Mineducación.

Navarrete, S., Candia, R., \& Puchi, R. (2013). Factores asociados a la deserción/retención de los estudiantes mapuche de la Universidad de la Frontera e incidencia de los programas de apoyo académico. Calidad en la educación, 43-80.

Resolución 01169, 01169 (Departamento de Prosperidad Social 01 de Julio de 2020).

Resolución 1970, 1970 (Departamento de Prosperidad Social 21 de Diciembre de 2012).

Sánchez, G., Barbosa , M., \& Castilla, H. (Octubre de 2017). Análisis de la deserción y los factores asociados a la permanencia estudiantil en una universidad peruana. Actualidades de Pedagogía, 1(69), 169-191.

Sevilla , D., Puerta Echavarría, V., \& Davila Molina, J. (2010). Influencia de los factores socioeconómicos en la deserción estudiantil de la carrera de ciencias sociales. Ciencia e Interculturalidad: Revista para el diálogo intercientífico e intercultural, 6(1), 74-84.

Esta obra está bajo una Licencia Creative Commons Attribución-NoCommercial 4.0 International

\section{(cc) EY-NO}

